\title{
Response to Dr. Murphy and Dr. Ferguson regarding comment on our paper: retrospective evaluation of antimicrobial prophylaxis in prevention of surgical site infection in the pediatric population
}

\begin{abstract}
SiR - We would like to thank Dr. Murphy and Dr. Ferguson for their interest in our manuscript. The primary issue raised involves our inclusion of children who did not receive antibiotics into the category of 'incorrect antibiotic administration' in our final date analysis (1). This is a valid point, but unfortunately the retrospective nature of the study did not allow us to delineate between patients who did not get antibiotics but needed them (incorrect) versus those who did not get them because the surgery was low risk. As such, we decided to include them all recognizing the potential bias to which Drs. Murphy and Ferguson allude.
\end{abstract}

Per their breakdown, after exclusion of those patients, the following two by two was constructed:

\begin{tabular}{lcc}
\hline & $\begin{array}{c}\text { 'Correct'antibiotic } \\
\text { administration }\end{array}$ & $\begin{array}{l}\text { 'Incorrect'antibiotic } \\
\text { administration }\end{array}$ \\
\hline $\begin{array}{l}\text { Surgical Site } \\
\text { Infection }\end{array}$ & 78 & 30 \\
$\begin{array}{l}\text { No Surgical Site } \\
\text { Infection }\end{array}$ & 2840 & 814 \\
\hline
\end{tabular}

From these data points, we agree that it can be concluded that there is no statistically significant difference in the rate of surgical site infection (SSI) between 'correct' and 'incorrect' antibiotic dosing (OR 1.34 [95\%
CI $0.88-2.1], P=0.2$ ). However, we would argue that even if we accept this premise, a $34 \%$ increase in SSI still represents a clinically if not statistically significant increase in this important outcome. Additionally, perhaps with a larger study significance may have been found. We thank Drs. Murphy and Ferguson again for their insight and agree with their statement that larger prospective trials are needed to truly answer this question.

\section{Source of funding}

No funding was received for this letter.

\section{Conflict of interest}

No conflicts of interest declared.

Goonjan S. Shah, Robert E. Christensen ${ }^{2} \&$ Alan R. Tait ${ }^{2}$
${ }^{1}$ Department of Anesthesiology, University of North Carolina,
Chapel Hill, NC, USA
${ }^{2}$ Department of Anesthesiology, University of Michigan Health
System, Ann Arbor, MI, USA
Emails: gshah@aims.unc.edu
doi:10.1111/pan.12598

\section{Reference}

1 Shah GS, Christensen RE, Wagner DS

et al. Retrospective evaluation of antimi- crobial prophylaxis in prevention of surgical site infection in the pediatric population. Pediatr Anesth 2014; 24: 994-998.

\section{We can't tell emergence agitation from pain, yet. Reply to: Stucke and Weisman 'Can we tell emergence agitation from pain?'}

SIR-We have read with interest the comments of Stucke and Weisman (1) regarding our study comparing preemptive clonidine or fentanyl on the incidence of emergence agitation (2). Stucke and Weisman challenged the accuracy of the diagnosis of pain used in our study pointing to the lower incidence of postoperative pain in other series with a similar surgical case mix $(3,4)$. They also suggest caution when using opioids to alleviate 